\title{
ARTICLE
}

Cite this: DOI: $10.1039 / \times 0 \times x 00000 x$

\section{Human oral cancer cells with increasing tumorigenic abilities exhibit higher effective membrane capacitance}

\author{
X Liang ${ }^{a}$, KA Graham ${ }^{b}$, AC Johannessen $^{a c}$, DE Costea ${ }^{a}$ and FH Labeed ${ }^{b}$
}

Received 00th January 2012, Accepted 00th January 2012

DOI: $10.1039 / \times 0 \times x 00000 x$

www.rsc.org/

\begin{abstract}
Objective: Although cells with tumorigenic / stem cell-like properties have been identified in many cancers, including oral squamous cell carcinoma (OSCC), their isolation and characterisation is still at early stages. The aim of this study was to characterise the electrophysiological properties of OSCC cells with different tumorigenic properties in order to establish if a correlation exists between tumorigenicity and electrical characteristics. Materials and Methods: Rapid adherence to collagen IV was used as a non-invasive, functional method to isolate subsets of cells with different tumorigenic abilities from one oral dysplastic and three OSCC-derived cell lines. The cell subsets identified and isolated by this method were further investigated independently using dielectrophoresis, a label-free method to determine their electrophysiological parameters. Cell membrane morphology was investigated using scanning electron microscopy (SEM) and modulated by use of 4-methylumbelliferone (4-MU). Results: The rapid adherent cells (RAC) to collagen IV, enriched for cells with increased tumorigenic ability, had significantly higher effective membrane capacitance than middle (MAC) and late (LAC) adherent cells. SEM showed that, in contrast to MAC and LAC, RAC displayed a rough surface, extremely rich in cellular protrusions. Treatment with 4-MU dramatically altered RAC cell membrane morphology by causing loss of filopodia, and decreased significantly their membrane capacitance, indicating that the highest membrane capacitance found in RAC was due to their particular cell membrane morphology. Conclusion: This is the first study showing that OSCC cells with higher tumour formation ability exhibit higher effective membrane capacitance than cells that are less tumorigenic. OSSC cells with different tumorigenic ability possessed different electrophysiological properties mostly due to their differences in the cell membrane morphology. The results suggest that dielectrophoresis may potentially be of use in the future for reliable, label-free isolation of putative tumorigenic cells.
\end{abstract}

\section{Introduction}

Oral cancer ranks as the sixth most common type of cancer world-wide ${ }^{1}$, with $90 \%$ of oral cancers being oral squamous cell carcinomas (OSCC). It has a 5-year survival rate of approximately $50 \%$, which has not improved during recent decades ${ }^{2}$, due in part to tumour recurrence following therapy. There is growing awareness that such recurrences may be related to patterns of cellular heterogeneity and tumour stemness within tumours. The presence of a subpopulation of cancer cells with stem cell-like properties (CSCs), including increased tumorigenesis has been shown in haematological cancers $^{3}$, as well as many solid cancers ${ }^{4}$, including OSCC ${ }^{5}$. These cells were also shown to have the ability to resist various apoptosis-inducing drugs, thus making therapeutic eradication of tumours very difficult and allowing tumour recurrence 6 Nevertheless, there are still many controversies about the presence and behaviour of cancer cells with stem cell-like properties/increased tumorigenic ability ${ }^{7}$, and more information is needed on their characteristics and behaviour in order to learn how one can target and annihilate them. The aim of this study was to characterise the OSCC cells with various tumorigenic abilities in terms of their electrophysiological properties and investigate whether they possess unique dielectrical features that can be putatively used in the future for their isolation.

The most common way of isolating tumorigenic/CSCs is fluorescence-activated cell sorting. For an expanding range of 
human epithelial tumours, including OSCC, differential expression of certain cell surface markers, primarily CD44 ${ }^{5 b}$, c, enzymatic activities (ALDH1) ${ }^{8}$ or exclusion of DNA dyes ${ }^{9}$ has enabled prospective identification and isolation of tumorigenic/CSCs. However, great debate surrounds the existence of specific phenotypic markers for tumorigenic cells in OSCC and in cancer in general ${ }^{10}$, since cancer cells are very versatile cells and have been shown to rapidly switch phenotypes, such that no specific markers are yet commonly accepted. There are, however, alternative ways to isolate tumorigenic/CSCs based on functional stem cell-like characteristics such as self-renewal (serial sphere formation), tumorigenicity (in vivo serial tumour engraftment), drug resistance (drug survival), or the presence of a certain niche (adhesiveness to specific substrates). For normal epithelium, the localization of self-renewing stem cells (label-retaining cells) near basal membranes (BM) that are rich in collagen IV indicates that collagen IV might be a component of the stem cell niche and suggests that adherence to collagen IV can be used for enriching in tumorigenic/CSCs. Previous studies on normal epithelium showed that the population of cells that were rapidly adhering to $\mathrm{BM}$ proteins contained the self-renewing population, and this method was shown to enrich stem cells in both human, murine and rabbit normal epithelium ${ }^{11}$. Adherence to $\mathrm{BM}$ components (collagen IV) was found to be crucial not only for normal cell growth, but also for tumour cell adhesion, growth, invasion and metastasis. The rapid adherence to collagen IV was also tested and proven to enrich for stem cells in epithelial malignancies such as hepatic carcinoma ${ }^{12}$, due to their differential expression of specific integrins ${ }^{13}$. We have chosen this method to identify and isolate cells with different tumorigenic/CSCs properties since it is a non-invasive, functional method that provides sorted cells with a non-altered phenotype.

To determine the electrophysiologal properties of the subsets of cells with different tumorigenic properties we have used dielectrophoresis. Dielectrophoresis (DEP) is an electrostatic phenomenon whose first in-depth study is attributed to Herbert Pohl in 1950, and is the name given to the movement of particles due to polarisation forces produced when the particles are subjected to an inhomogeneous electric field ${ }^{14}$. Cells can polarise in an electric field because unequal concentrations of charges at the interfaces between the cell and suspending medium causes the formation of a dipole across the cell membrane (e.g. between the intracellular contents and the surrounding medium) along the direction of the electric field lines. Interaction of the two dipole charge centres with a field gradient creates non-equal opposing Coulombic forces, resulting in a net force and driving cellular movement in the direction of the field gradient. The force acting on the cells (FEEP) is defined in Equation 1, where $r$ is the radius of the spherical body, $\varepsilon_{m}$ the relative permittivity of the surrounding medium, $\varepsilon_{o}$ is the permittivity of free space and $\nabla E^{2}$ is the square of the gradient of the strength of the applied electric field ${ }^{14 b}$

$$
\mathbf{F}_{\mathrm{DEP}}=2 \pi \varepsilon_{o} \varepsilon_{r} r^{3} \operatorname{Re}[K(\omega)] \nabla \mathrm{E}^{2}
$$

Re indicates "the real part of" and $K(\omega)$ refers to the ClausiusMossotti factor, a complex term dependent on the dielectric properties of the medium and cellular components, and dependent on the frequency of the energising electric field. It is this parameter which, when analysed as a function of frequency, allows the cellular dielectric characteristics to be elucidated. The resultant "DEP spectrum" 15 can be directly related via a scaling factor to the value of $\operatorname{Re}[K(\omega)]$ at that frequency and from this, certain electrophysiological parameters can be found, namely the cytoplasmic conductivity, effective membrane conductance ( $\mathrm{G}_{\text {eff }}$ ) and effective membrane capacitance $\left(\mathrm{C}_{\text {eff }}\right)$. Cytoplasmic conductivity reflects the electrical charge contained within the cytoplasm, and therefore is indicative of ionic strength. Effective membrane conductance $\left(\mathrm{G}_{\text {eff }}\right)$ relates to ionic transport across the cellular membrane, and effective membrane capacitance $\left(\mathrm{C}_{\text {eff }}\right)$ is indicative of the morphology or phenotype of the cellular membrane. DEP testing can be used to measure these properties, allowing it to be used as a characterisation tool

DEP was first used on living cells by Pohl and Hawk in $1966^{16}$, but has since been used to both characterise and separate different populations of cells, for a variety of different purposes within biology and medicine, such as to study links between multidrug resistance and cancer, and to study apoptosis ${ }^{17}$. DEP has been employed in a micro-fluidic chip to separate colorectal cancer cells from E.coli bacteria and Human Embryonic Kidney 293 cells ${ }^{18}$. Dielectric methods have also been used to separate breast cancer cells from blood ${ }^{19}$, and to distinguish stem cells from their progeny ${ }^{20}$. Recently, DEP has been used to study the electrical effects of sphingosine on mouse ovarian cancer progression models ${ }^{21}$ and discriminate normal oral cells from pre-cancerous and neoplastic oral cell lines ${ }^{22}$. DEP offers many advantages over other methods of measuring cell electrophysiology; it requires no markers and is not confounded by cell-marker interactions (unlike flow cytometry ${ }^{17}$ ), and can examine many cells (typically 1000+) simultaneously, unlike patch clamp (where costly high-throughput systems have much lower throughput).

This study is the first to examine primary human tumor initiating cells by dielectrophoresis. The analysis showed that there are marked electrophysiological differences between oral cancer cells with different tumorigenic properties. The differences appear to culminate around the membrane effective capacitance and seem to be related to a cell membrane very rich in cellular protrusions. In this study, the method of separation of OSCC cells relied on their differential adhesiveness to collagen IV, hence highlighting it as a simple and robust method to sort rapid adherent cells (RAC) enriched with tumorigenic properties, middle (MAC) and late (LAC) adherent cells that show gradual loss of the tumorigenic abilities.

Further, the overall results suggest that DEP could potentially be used as a reliable, label-free tool for the isolation of putative oral cancer tumorigenic cells. 


\section{Materials and methods}

\section{Cell culture}

Oral dysplastic / premalignant cell lines DOK ${ }^{23}$ and the human cell lines $\mathrm{H} 357^{24}$, CaLH3 ${ }^{5 c}$, OSCC1 ${ }^{6,25}$, derived from patients with OSCC were used in this study. CaLH3 and OSCC1 cell lines were obtained in-house from patients with OSCC after informed consent, and grown as previously described ${ }^{6}$. DOK, H357 and CaLH3 were grown routinely in the so called 'FAD' medium $^{26}$, a 3:1 mixture of Dulbecco's Modified Eagle's Medium (DMEM) and Ham's F12 supplemented with 10\% Foetal Bovine Serum (FBS), $25 \mu \mathrm{g} / \mathrm{ml}$ Bovine Pituitary Extract (InVitrogen,USA), $0.4 \mu \mathrm{g} / \mathrm{ml}$ hydrocortisone, $5 \mu \mathrm{g} / \mathrm{ml}$ insulin (Novo Nordisk, Bagsværd, Denmark), $20 \mu \mathrm{g} / \mathrm{ml}$ transferrin, 50 $\mu \mathrm{g} / \mathrm{ml}$ L-ascorbic acid, $20 \mu \mathrm{g} / \mathrm{ml}$ L-glutamine. OSCC1 were grown routinely in keratinocyte serum free medium (KSFM, InVitrogen) supplemented with $1 \mathrm{ng} / \mathrm{mL}$ EGF, $25 \mu \mathrm{g} / \mathrm{mL}$ BPE, $100 \mathrm{U} / \mathrm{mL}$ penicillin, $100 \mu \mathrm{g} / \mathrm{mL}$ streptomycin and $0.25 \mu \mathrm{g} / \mathrm{mL}$ amphotericin B (all from GibcoBRL, Grand Island, NY, USA). All cells were grown under standard cell culture conditions: a humidified incubator at $37{ }^{\circ} \mathrm{C}$ and 5\% CO2/ 95\% air. At 60$70 \%$ confluence, the cells were released using $0.25 \%$ trypsinEDTA. All reagents were supplied by Sigma Aldrich, (St. Louis, MO, USA) unless otherwise indicated.

\section{Adherence to collagen IV}

Tissue culture dishes $(100 \mathrm{~mm})$ were coated evenly with $10 \mu \mathrm{g} / \mathrm{ml}$ human collagen IV (BD Biosciences, Franklin Lakes, USA) diluted in $10 \mathrm{mM}$ acetic acid. After incubation at room temperature for 1 hour, the remaining collagen IV solution was aspirated and the dishes were twice rinsed carefully with phosphate-buffered saline (PBS), to remove any remaining acetic acid. The coated dishes were sterilised overnight using UV radiation. Single-cell suspensions in medium were allowed to attach to the tissue culture dishes coated with collagen IV in the incubator. Cells that attached to the dishes within $10 \mathrm{~min}$ were collected after trypsinisation and referred to as rapid adherent cells (RAC). The cells that remained unattached within the first $10 \mathrm{~min}$ were then transferred to a new, sterile collagen IV-coated dish for an additional $30 \mathrm{~min}$ in the incubator. Cells that adhered within this period were referred to as middle adherent cells (MAC). All remaining unattached cells were collected as late adherent cells (LAC). The sorted cells using this method were further tested for their tissue regeneration and tumour initiating properties.

\section{Three-dimensional organotypic assay}

Three-dimensional (3D) organotypic co-cultures were obtained by seeding dysplastic (DOK) and neoplastic oral keratinocytes on top of collagen type I biomatrices populated with carcinoma associated fibroblasts, using a protocol established in our laboratory ${ }^{27}$. The organotypic cultures were grown in serum free culture medium: 3 vol. Dulbecco's Modified eagle's medium (Sigma)/1 vol. Ham's F 12 (Sigma), supplemented with $0.4 \mu \mathrm{g} / \mathrm{ml}$ hydrocortisone (Sigma), $5 \mu \mathrm{g} / \mathrm{ml}$ Insulin (Novo Nordisk, Bagsværd, Denmark), $20 \mu \mathrm{g} / \mathrm{ml}$ transferrin (Sigma), $50 \mu \mathrm{g} / \mathrm{ml}$ L-ascorbic acid (Sigma), $1 \mathrm{mg} / \mathrm{ml}$ linoleic acidalbumin (Sigma), $200 \mu \mathrm{g} / \mathrm{ml}$ penicillin, $200 \mu \mathrm{g} / \mathrm{ml}$ streptomycin,
$0.5 \mu \mathrm{g} / \mathrm{ml}$ amphotericin B, $6 \mu \mathrm{g} / \mathrm{ml}$ fluconazole, $20 \mu \mathrm{g} / \mathrm{ml} \mathrm{L-}$ Glutamine. The cultures were lifted at air-liquid interface and harvested after 10 days, formalin fixed and paraffin embedded or fresh-frozen, as previously described 27.

\section{Tongue xenotransplantation assay in NOD/SCID mice}

NOD/SCID mice with the age of 6-8 weeks were used and kept in an isolation facility under pathogen-free conditions and a 12hour day/night cycle. All animal procedures were approved by the Norwegian Animal Research Authority. Cells suspended in $50 \mu 1$ of matrigel (BD Biosciences) were injected into the tongue of mice. Tumor formation was visualized and assessed at the onset of symptoms.

\section{DEP experiments}

Homogeneous cell suspensions were prepared and centrifuged at room temperature at $190 \times \mathrm{g}$ for 5 minutes. To ensure complete removal of highly conductive culture medium, the cell suspensions were washed twice and re-suspended in fresh isotonic medium for DEP experimentation, consisting of $8.5 \%$ $(\mathrm{w} / \mathrm{v})$ sucrose and $0.3 \%(\mathrm{w} / \mathrm{v})$ dextrose ${ }^{28}$. Cells were used immediately after re-suspension to minimise the effects of suspension in low-conductivity medium. The medium conductivity was adjusted to $10 \mathrm{mS} / \mathrm{m}$ using $\mathrm{PBS}$ and the final conductivity was verified by a Jenway 470 conductivity meter (VWR Jencons, Leicestershire, UK). A small sample of the final cell suspension was stained with Trypan blue and counted using a Bürker haemocytometer chamber and adjusted to $1.2 \times 10^{5}$ cells $/ \mathrm{ml}$ for all DEP measurements. The "DEP Well chip" 3D well electrode (DEPtech, Uckfield, UK) and associated MATLAB (The MathWorks Inc, Nantick, MA) control and analysis software used in this study are described in detail elsewhere ${ }^{29}$. The chip was analysed using a prototype 3DEP reader (Labtech, Uckfield, UK) with measurements taken using 10v p-p sinusoidal signals applied for 60 seconds, with measurements every 3 seconds. The change in light intensity across the well was measured for each frequency; a "best-fit" of the real part of the Clausius-Mossotti factor $(\operatorname{Re}[k(\omega)])$ versus frequency was then found for the corresponding spectrum using the "single shell model" approach ${ }^{29}$ and the following variables: cytoplasmic conductivity $(\mathrm{S} / \mathrm{m})$, effective membrane conductance $\left(\mathrm{S} / \mathrm{m}^{2}\right)$ and effective membrane capacitance $\left(\mathrm{F} / \mathrm{m}^{2}\right)$. Each experiment was repeated three times for $\mathrm{CaLH} 3$ cell line and two times for $\mathrm{H} 357$ and OSCC1 cell lines. Cell diameters were measured using Image $\mathbf{J}$ software and the microscope images of at least 50 cells were analysed, for each cell type, to determine cell radii for subsequent DEP modelling. Scanning Electronic Microscopy (SEM)

RAC, MAC and LAC were obtained from CaLH3 and H357 cell lines. They were detached from the collagen coated surfaces, counted and resuspended in a single cell suspension; 500 cells of each RAC, MAC and LAC subset of cells were allowed to attach for $1.5 \mathrm{hrs}$ to the poly-lysine-coated coverslips in 24 wells plates (VWR International AS, Oslo, Norway), at $37^{\circ}$. Samples were then fixed with $2 \%(\mathrm{v} / \mathrm{v})$ glutaraldehyde in $0.1 \mathrm{M}$ phosphate buffer $(\mathrm{pH}=7.2)$ for $2 \mathrm{hrs}$ at $4^{\circ} \mathrm{C}$. Fixed samples were then subjected to graded ethanol dehydration and critical point dried, mounted on aluminium 
stubs, and coated with evaporated carbon, for the visual analysis performed using a Jeol JSM-7400 field emissionscanning electron microscope.

\section{Treatment with 4-methylumbelliferone (4-MU)}

The sodium salt 4-MU (Sigma), as a hyaluronic acid (HA) synthesis inhibitor,was dissolved in distilled water at a concentration of $0.3 \mathrm{mM}$. This stock solution was appropriately diluted in the respective cell culture medium. CaLH3 and OSCC1 cells were grown routinely until approximately 50\% confluent, and then incubated in the presence of 4-MU for 48 hrs. The experiment was repeated three times.

\section{Statistics}

Data are expressed as mean \pm standard error of the mean (StEM) or standard deviation (SD) using GraphPad Prism software version 5.00 for Windows (GraphPad Software, San Diego, California, USA, www.graphpad.com) and SPSS programme (PASW Statistics 18, IBM, New York, USA). The differences in $\mathrm{C}_{\text {eff }}, \mathrm{G}_{\text {eff, }}$ cytoplasmic conductivity, and cell diameter between different cell subpopulations were analysed using ANOVA and the paired student t-test after relative data transformation to fulfil the assumption of normality. Paired student t-test was also used to analyse the $\mathrm{C}_{\text {eff, }} \mathrm{G}_{\text {eff }}$ and cytoplasmic conductivity values before and after 4-MU treatment in CaLH3 cell line.

\section{Results}

RAC isolated from the oral dysplastic cell line DOK gave rise to a dysplastic epithelium that had the highest thickness in 3D organotypic cultures.

To test the regenerative potential of RAC, MAC and LAC, 3D organotypic culture were constructed separately by growing for 10 days each of these cell sub-populations isolated from the oral dysplastic cells DOK on top of a fibroblast-populated collagen biomatrix. All subpopulations gave rise to a dysplastic epithelium, but RAC formed a thicker epithelium (33.78 \pm 19.60$)$ when compared to MAC $(20.02 \pm 16.48)$ and LAC (27.00 \pm 16.16$)$ for (Fig. 1A and B).

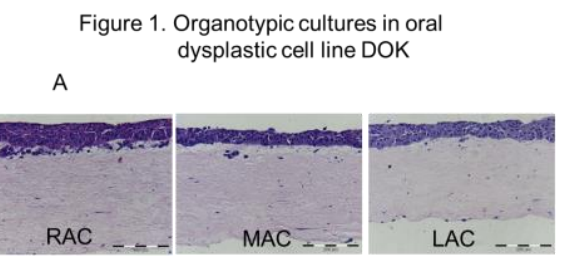

$\mathrm{B}$

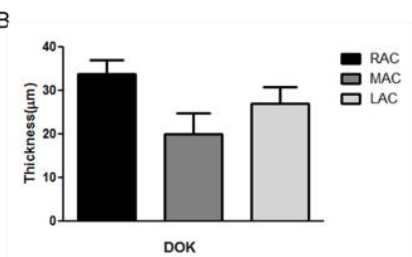

Figure 1. Quantification of the electrophysiological parameters for RAC, MAC and LAC subpopulations of cells isolated from CaLH3, H357 and OSCC1 cell lines: A). RAC displays the thickest epithelium among three different sub-populations. B). Quantification of thickness in organotypic cultures by RAC, MAC and LAC.
RAC isolated from OSCC-derived cells showed great tumor formation efficiency and shorter lag time of tumor formation than LAC in NOD/SCID mice.

To test the tumor initiating potential of RAC, MAC and LAC isolated from OSCC1 cell line, serial dilutions of these three subpopulations were xenotransplanted in the tongues of NOD/SCID mice $(n=35)$. RAC $(82 \%)$ showed higher tumor incidence than MAC (58\%) and LAC (42\%) (Fig. 2A,a). When as low as 100 cells were injected, RAC formed the tongue tumor at the early lag time $(20.33 \pm 3.5), 5$ days before the tumor formation in LAC $(25.33 \pm 9.90)$, but the similar when compared

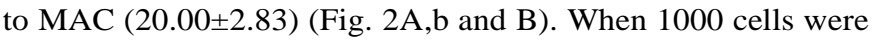
xenotransplanted, RAC and MAC formed the primary tumors 7 days earlier compared to LAC (Fig. 2A and C). This indicates that the cells sorted based on adherence to collagen IV showed decrease in tumor formation ability from RAC to MAC to LAC.

Figure 2. Tumor initiating ability for NOD/SCID
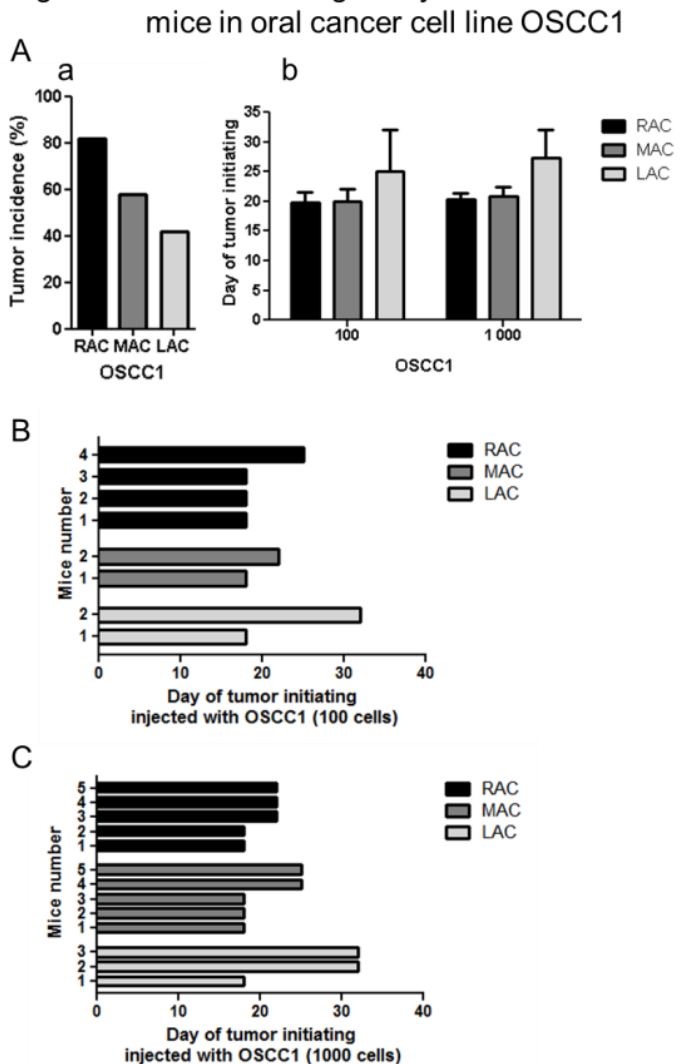

Figure 2. Tumor initiating ability of RAC, MAC and LAC subpopulations of cells isolated from OSCC1 cell lines in NOD/SCID mice: A) a. RAC showed highest tumor incidence among RAC, MAC and LAC. b. RAC had earlier tumor initiating time than LAC, but similar time point with MAC. B) Individual tumor initiating time formed by 100 cells of RAC MAC and LAC. C) Individual tumor initiating time formed by 1000 cells of RAC MAC and LAC.

RAC showed the highest effective membrane capacitance $\left(\mathrm{C}_{\text {eff }}\right)$, but no consistent trend was found between RAC, MAC and LAC in terms of effective membrane conductance $\left(G_{\text {eff }}\right)$ or 
cytoplasmic conductivity for both oral dysplastic and neoplastic cell lines.

RAC, MAC and LAC displayed significant differences in terms of $\mathrm{C}_{\text {eff }}$ when all oral cancer cell lines were analysed together $(p<0.001)$. For oral cancer cell lines, paired student's t test showed that RAC had the highest effective membrane capacitance $\left(\mathrm{C}_{\text {eff }}, \mathrm{mF} / \mathrm{m}^{2}\right)\left(18.10 \pm 3.28 \mathrm{mF} / \mathrm{m}^{2}\right), 20.26 \%$ higher when compared to MAC $\left(15.05 \pm 2.74 \mathrm{mF} / \mathrm{m}^{2}, \mathrm{p}=0.026\right)$ and $79.65 \%$ higher than LAC $\left(10.08 \pm 1.65 \mathrm{mF} / \mathrm{m}^{2}, \mathrm{p}<0.001\right)$. MAC had also a significantly higher $\mathrm{C}_{\text {eff }}$ than LAC $(\mathrm{p}=0.018)$. There were some variations in the extent of differences between RAC, MAC and LAC with the type of cancer cell line analysed, and although the differences were statistical significant between RAC, MAC and LAC in CaLH3 cell line only $(\mathrm{p}=0.011)$, the other two cell lines analysed showed the same trend of decreased $\mathrm{C}_{\text {eff }}$ with decrease in stem cell-like properties (Fig. $3 \mathrm{~A})$. For oral dysplastic cell line DOK, the same trend was found in effective membrane capacitance (Fig. 4A).

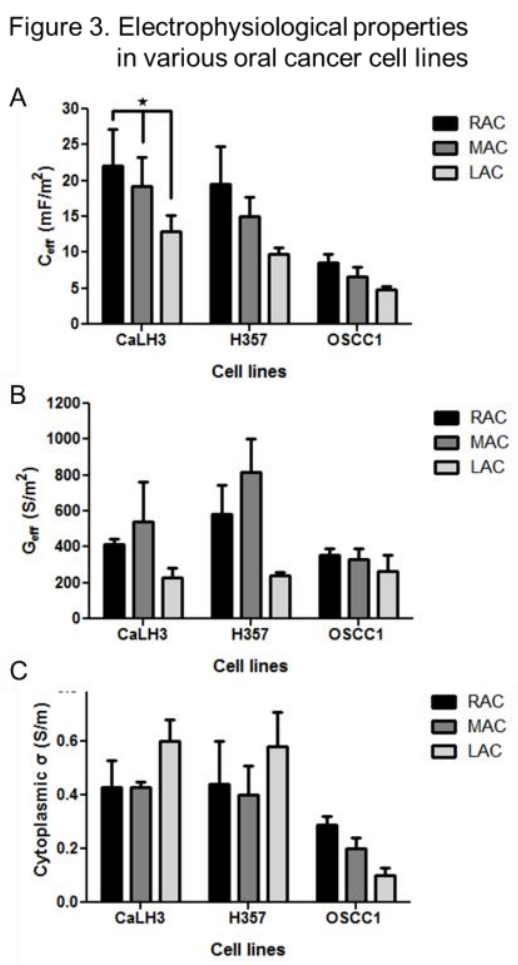

Figure 3. Quantification of the electrophysiological parameters for RAC, MAC and LAC subpopulations of cells isolated from CaLH3, H357 and OSCC1 cell lines: A). RAC displays the highest effective membrane capacitance $\left(\mathrm{C}_{\text {eff }}\right)$. B). No consistent trend could be observed between RAC, MAC and LAC in terms of effective membrane conductance $\left(\mathrm{G}_{\text {eff }}\right)$ or $\left.\mathrm{C}\right)$ cytoplasmic conductivity. Data are presented as mean StEM of three (CaLH3) and two (H357 and OSCC1) experiments. Star indicates statistically significant differences with a $\mathrm{p}$ value < 0.05. Double star indicates statistically significant differences with a $\mathrm{p}$ value $<0.01$.

showed no consistent trend (Fig. 3B) from RAC (454.03 \pm $\left.63.66 \mathrm{~S} / \mathrm{m}^{2}\right)$ to MAC $\left(585.72 \pm 113.64 \mathrm{~S} / \mathrm{m}^{2}\right)$ to $\operatorname{LAC}(243.76 \pm$
$28.61 \mathrm{~S} / \mathrm{m}^{2}$ ). Minimal differences were detected between RAC, MAC and LAC for cytoplasmic conductivity $(0.40 \pm 0.07 \mathrm{~S} / \mathrm{m}$, $0.36 \pm 0.05 \mathrm{~S} / \mathrm{m}$, and $0.44 \pm 0.08 \mathrm{~S} / \mathrm{m}$, respectively), and no consistent trend could be observed from cells enriched in stem cell-like properties (RAC) towards cells that lost stem cell-like properties (LAC) (Fig. 3C). The similar trend was found in dysplastic cell line DOK (Fig. 4B and C).
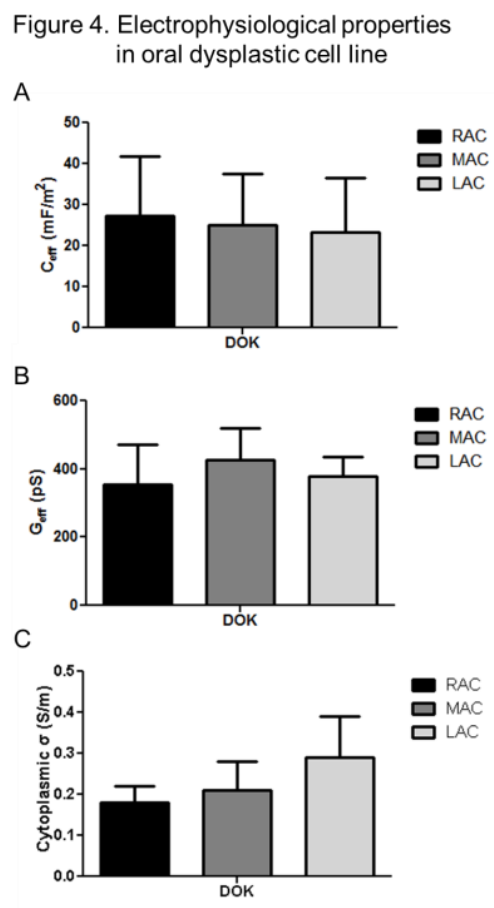

Figure 4. Quantification of the electrophysiological parameters for RAC, MAC and LAC subpopulations of cells isolated from oral dysplastic cell line DOK: (A). RAC displays the highest effective membrane capacitance ( $\mathrm{C}_{\text {eff }}$ ). (B). No consistent trend could be observed between RAC, MAC and LAC in terms of effective membrane conductance $\left(\mathrm{G}_{\text {eff }}\right)$ or $(\mathrm{C})$ cytoplasmic conductivity. Data are presented as mean StEM of three $(\mathrm{CaLH} 3)$ and two (H357 and OSCC1) experiments.

RAC were smaller and displayed a more folded and ruffled cell membrane than MAC and LAC for both oral dysplastic and neoplastic cell lines.

Since the differences detected in this study were mostly at the effective membrane capacitance level, known to be influenced by the morphology of the cellular membrane, we further investigated morphology-related aspects of the three subsets of cells we have used in the study. For oral cancer cell lines, RAC were found to have a significantly smaller diameter (13.46 \pm $0.23 \mu \mathrm{m})$ than MAC $(13.80 \pm 0.21 \mu \mathrm{m}, \mathrm{p}=0.004)$ and LAC (14.98 $\pm 0.23 \mu \mathrm{m}, \mathrm{p}=0.000$ ) (Fig. 5B). MAC had also a significantly smaller diameter than LAC $(\mathrm{p}=0.000)$ (Fig. 5B). This appearance was consistent with all oral dysplastic cell line DOK (Fig. 5C).

SEM revealed that RAC had a more regular spherical shape but displayed a more folded and ruffled cell membrane surface, rich in both filopodia and lamellipodia membrane protrusions, with 
the predominance of the first ones (Fig. 5A). In contrast, MAC and LAC were more heterogeneous and had a flat appearance, with smoother cell borders and less cellular protrusions on the surface (Fig. 5A). This appearance was consistent for all oral dysplastic and cancer cell lines examined in the study.

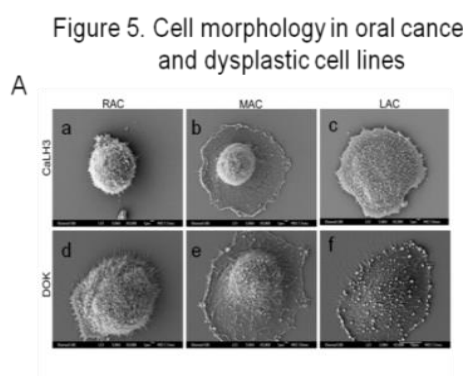

B

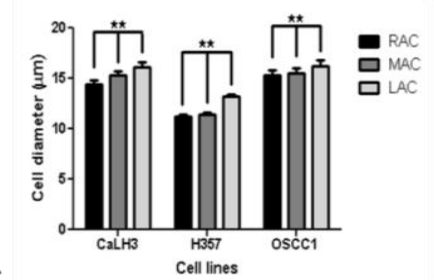

C

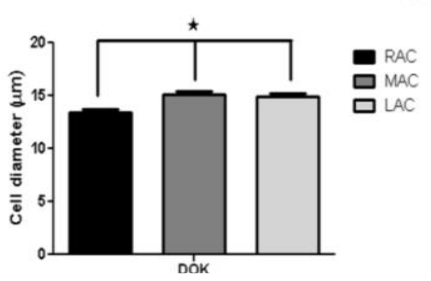

Figure 5. (A). SEM images of RAC, MAC and LAC from oral cancer cell line CaLH3 and oral dysplastic cell line DOK: (a, d) RAC exhibited a regular, round shape and a ruffled cell surface, densely covered with cellular protrusions and extremely reach in cell protrusion. (c, e) MAC displayed a regular, round shape as well, but showed a surface less densely covered with cellular protrusions. $(d, f)$ LAC cells showed an irregular shape and a flatten surface, with less cellular protrusions. (B, C). Quantification of the cell diameter of RAC, MAC and LAC subpopulations of cells isolated from oral cancer cell lines CaLH3, H357 and OSCC1 cell lines and oral dysplastic cell line DOK (C): RAC are the smallest cells. C) Quantification of the cell diameter of RAC. Data are presented as mean StEM of minimum 50 cells in three different experiments. Star indicates statistically significant differences with a $\mathrm{p}$ value value $<0.05$. Double star indicates statistically significant differences with a $\mathrm{p}$ value $<0.01$.

Treatment with 4-MU induced loss of filopodia and decreased Ceff of RAC in CaLH3 cell line.

In order to determine whether the cell membrane morphology was the key parameter for the difference in the $\mathrm{C}_{\text {eff }}$ observed between the three subsets of cells, we have altered it by treatment with the small molecule inhibitor of HA synthesis, 4MU. 4-MU was previously shown to induce changes of the membrane morphology of OSCC cells through inhibition of hyaluronic acid chain elongation 37. Treatment with 4-MU and subsequent SEM showed a loss of filopodia and smoothening of the cell membrane of RAC cells compared to non-treated RAC, and similar to the cell surface of LAC (Fig. 6A). DEP analysis of cells treated with 4-MU for $48 \mathrm{hrs}$ showed a significant decrease in $\mathrm{C}_{\mathrm{eff}}$ in RAC from $23.39 \pm 4.04 \mathrm{mF} / \mathrm{m}^{2}$ to $10.41 \pm 0.76 \mathrm{mF} / \mathrm{m}^{2}(\mathrm{p}=0.031)$ in $\mathrm{CaLH} 3$ cell line. No difference was detected in the $\mathrm{C}_{\mathrm{eff}}$ of RAC, MAC and LAC cells after treatment with 4-MU in CaLH3 cell line (Fig. 6B). In another cell line OSCC1, $\mathrm{C}_{\text {eff }}$ was shown a slight decrease in RAC but not in MAC and LAC (Fig. 6C). 4-MU did not significantly alter the other electrophysiological parameters investigated in the study.

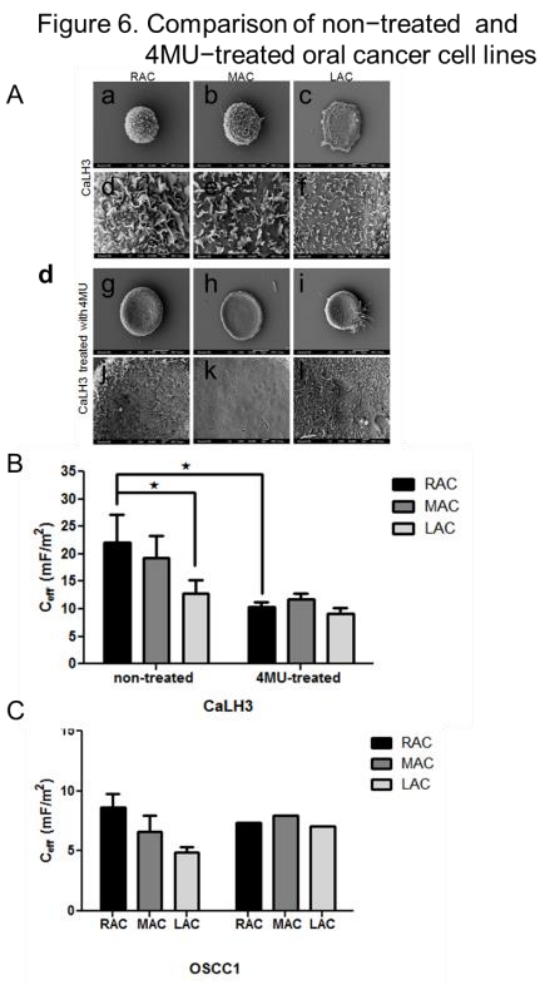

Figure 6. SEM images of RAC, MAC and LAC from CaLH3 cell line. RAC exhibited a regular, round shape (a) and a ruffled cell surface, densely covered with cellular protrusions and extremely rich in filopodia (d). MAC displayed a regular, round shape as well (b), but showed a surface less densely covered with cellular protrusions and not so rich in filopodia (e). LAC cells showed an irregular shape (c) and a flattened surface, with fewer and shorter filopodia (f). Treatment with 4MU induced a flatter surface on all cell subsets and a loss of filopodia, especially in RAC and MAC (g-1).

\section{Discussion}

This study produces the first evidence inthe electrophysiological properties of oral cancer cell subsets with different tumorigenic/stem cell-like properties. The results highlighted a correlation between tumour regeneration (tumorigenicity) and electrophysiological properties. The higher the tumourgenesis capacity of the OSCC cells, the higher was the effective membrane capacitance found. To separate subsets of OSCC cells with different tumorigenic/stem 
cell-like properties we have chosen here a functional method based on the cellular adherence to collagen IV. This method has been reported to successfully enrich for cells with stem cell-like properties in various epithelial tissues, such as normal human skin ${ }^{13}, 30$. This method has been shown to robustly sort cell populations with different self-renewing capacities 13 and different potential for regenerating normal skin ${ }^{30}$ and OSCC ${ }^{5 a}$. We have chosen to use this method for CSC enrichment since it avoids possible cell surface modifications that might occur due to antibody binding, and thus prevents any alterations of their original electrophysiological properties that would occur after marker-based cell sorting. In this way, we are confident that we have preserved in the best possible way the original characteristics of the cells for a valid DEP characterization of the subsets of cells with different tumorigenic/stem cell-like properties (RAC, MAC and LAC). On the other hand, this method has also its limitations. The enrichment in tumorigenic/CSCs through increased adherence to collagen IV is related to increased expression of $\beta 1$ integrin on the surface of stem cell-like cells ${ }^{13}$, and although it does not directly use antibody binding for cell sorting, it is still related to a specific phenotype that can vary with the epithelium type (squamous or simple versus transitional) ${ }^{31}$, or culture conditions. Nevertheless, our results indicate that the RAC subset of cells, although not exclusively containing tumorigenic/CSCs, is enriched in cells with increased self-renewal and increased tumorigenicity, two essential attributes of CSCs.

We further show here that the subset of OSCC cells enriched in cells with tumorigenic abilities / stem cell-like properties (RAC) possess different electrophysiological properties than the rest of the cancer cells (MAC and LAC) due to their unique membrane characteristics. RAC displayed the highest $\mathrm{C}_{\text {eff }}$ when compared to the other sub-populations of oral cancer cells tested (MAC and LAC). Whilst $\mathrm{C}_{\text {eff }}$ may be affected by membrane composition (including lipid type and protein composition) ${ }^{32}$, it is most strongly influenced by the membrane surface area, which is in turn related to the morphology of the cell membrane. When the cellular morphology of our three subsets of cells was analysed further, SEM showed marked differences between their cell membrane morphology, with RAC showing a cellular membrane morphology very rich in cellular protrusions. We report here for the first time that cancer-stem cell like cells have a unique cell membrane morphology, enriched in filopodia. The biological significance of this ruffled cell membrane morphology is not yet elucidated, and especially not in pathological conditions such as cancer. In the normal state, the homeostasis, the shape of cellular membrane is of major importance for the control of cell signalling and cellular processes: invaginations of the plasma membrane allow forming endocytic vesicles that remove signalling molecules from the cell surface; conversely, plasma protrusions into the extracellular space allow a cell to probe its environment. Our results are in line with the very few studies on the ultrastructure of adult stem cells that show, for example, that undifferentiated mesenchymal stem cells have a cell surface covered by filopodia and undulopodia. During differentiation, the mesenchymal stem cells changed their shape from a round to a fibroblastic-like shape and lose their protrusions ${ }^{33}$. Also in neurogensis, the abundance of other cellular protrusions, such as apical microvilli, decrease as well with the onset of differentiation ${ }^{34}$, and two signaling pathways known to regulate the proliferation versus differentiation of neural progenitors (Sonic Hedgehog and Wnt signaling) have been linked with the regulation of these cellular protrusions ${ }^{35}$. Other observations pointing to a more ruffled cell membrane surface in epithelial stem-like cells come also from studies on the localization of prominin-1 (CD133), a marker for both hematopoietic and epithelial stem cells that was selectively found on plasma membrane protrusions. In addition, this seemed to be a general characteristic non-cell type dependent since it showed in both epithelial and transfected non-epithelial cells a selective association with apical microvilli and plasma membrane protrusions, respectively ${ }^{36}$. Of interest, the embryonic stem cells seem to be, in contrast, characterised by a smoother cell surface and many investigators relate the presence of cellular protrusions to the cellular process of invasion. Using anchor cell invasion into the vulvar epithelium in C. elegans is an in vivo model of invasive behaviour that allows for genetic and single-cell visual analysis of invasion, investigators have shown that generation of robust protrusions that breach the $\mathrm{BM}$ is responsible for their invasion and that this is due to a particular cell signalling and molecular mechanism ${ }^{37}$. Although we did not aim to identify the molecular mechanisms that are responsible for the generation of the cellular protrusions in RAC, the fact that 4-MU smoothens their surface indicates a role for hyaluronic acid and its complex biology in the formation of these cellular protrusions. This also indicate that the presence of these numerous filopodia might be related to increased migration and invasion of RAC cells, as suggested by the fact that treatment of OSCC-derived cell lines with 4-MU induced a decrease in its migration through transwells (data not shown). The association between a cell membrane morphology reach in cellular protrusions and increased migration in cancer stem cells fits also very well with the new theory of CSCs as the more migratory, cancer cell population ${ }^{38}$.

Of importance for our study is that the presence of a cell membrane morphology rich in cellular protrusions could explain the highest $\mathrm{C}_{\text {eff }}$ detected in RAC. Our hypothesis that the ruffled membrane morphology of RAC cells was the main determinant of their high $\mathrm{C}_{\text {eff }}$ was proven by the finding that treatment with 4-MU dramatically altered the membrane morphology of all RAC cells by loss of filopodia and this was also translated in a significant decrease of $\mathrm{C}_{\text {eff, abolishing the }}$ difference observed initially between the three subsets of cells. The change in capacitance could also be related to changes in the permittivity of the membrane due to the action of 4-MU in shortening the HA chains; however, we suggest that of the two mechanisms, the effects of morphology charge are likely to significantly outweigh those of permittivity change. The unique differences in the membrane electrophysiological properties of stem-like cells is in line with a recent finding from our group 
showing that cell membrane dielectric properties could potentially be used as a marker for stem cells in neural tissues 39 . With a lack of distinct stem cell markers, isolation of tissuespecific stem cells for tissue engineering and gene therapy is a great challenge. More functional and non-invasive methods for tumorigenic/stem cell isolation are sought. The results of this study suggest that DEP might be used in the future as a reliable, label-free and non-invasive method for putative isolation of tumorigenic cell in oral cancer.

\section{Conclusions}

To our knowledge, this is the first study to show that OSCC cells with higher tumour formation (tumorigenecity) exhibit higher effective membrane capacitance than cells with less tumorigenicity. OSCC with different stem cell-like properties possessed different electrophysiological properties, mostly due to their differences in cell membrane morphology which was found to be very rich in cellular protrusions. The study shows the potential use of effective membrane capacitance as a potential tumorigenic/stem cell-like marker. The results suggest that dielectrophoresis may potentially be of use in the future for reliable, label-free isolation of putative tumorigenic/cancer stem cells.

\section{Acknowledgements}

The authors would like to thank the staff of both The Gade Laboratory of Pathology, University of Bergen, Norway and The Centre for Biomedical Engineering, University of Surrey, UK, especially Prof. Michael Hughes for his valuable discussions, Dr Hayley J. Mulhall, Dr Rula Abdallat and Ms. Endy Spriet (at Molecular Imaging Center (MIC), University of Bergen) for their technical assistance. Special thanks to statistician Jannicke Igland from the Department of Public Health and Primary Health Care. The study was supported by The Norwegian State Educational Loan Fund (Quota Programme, XL), Bergen Medical Research Foundation (20/2009), Norwegian Cancer Association (515970/2011), Meltzer's fund (project no: 804513, XL), Engineering and Physical Research Council (EPSRC, project no. 112982), and Collaboration Fund/Finance South East.

\section{Notes}

${ }^{a}$ The Gade Laboratory for Pathology, Department of Clinical Medicine, Faculty of Medicine and Dentistry, University of Bergen, 5021, Bergen, Norway

${ }^{b}$ Centre for Biomedical Engineering, Mechanical Engineering Sciences, University of Surrey, Guildford, GU2 7XH, UK

c Department of Pathology, Haukeland University Hospital, 5021, Bergen, Norway.

\section{References}

1. D. M. Parkin, F. Bray, J. Ferlay, P. Pisani, Global cancer statistics, 2002. CA Cancer J Clin 2005, 55. 74-108.

2. (a) A. I. Zavras, A. J. Yoon, M. K. Chen, C. W. Lin, S. F. Yang, Metallothionein-1 genotypes in the risk of oral squamous cell carcinoma. Ann Surg Oncol 2011, 18. 1478-83, DOI: 10.1245/s10434-010-1431-3; (b) L. Mao, W. K. Hong, V. A. Papadimitrakopoulou, Focus on head and neck cancer. Cancer Cell 2004, 5. 311-6; (c) B. M. Wensing, M. A. Merkx, P. F. Krabbe, H. A. Marres, F. J. Van den Hoogen, Oral squamous cell carcinoma and a clinically negative neck: the value of follow-up. Head Neck 2011, 33. 1400-5, DOI: 10.1002/hed.21642.

3. D. Bonnet, J. E. Dick, Human acute myeloid leukemia is organized as a hierarchy that originates from a primitive hematopoietic cell. Nature medicine 1997, 3. 730-7.

4. (a) T. Reya, S. J. Morrison, M. F. Clarke, I. L. Weissman, Stem cells, cancer, and cancer stem cells. Nature 2001, 414. 105-11, DOI: 10.1038/35102167; (b) M. Al-Hajj, M. S. Wicha, A. Benito-Hernandez, S. J. Morrison, M. F. Clarke, Prospective identification of tumorigenic breast cancer cells. Proceedings of the National Academy of Sciences of the United States of America 2003, 100. 3983-8, DOI: 10.1073/pnas.0530291100; (c) C. Li, D. G. Heidt, P. Dalerba, C. F. Burant, L. Zhang, V. Adsay, M. Wicha, M. F. Clarke, D. M. Simeone, Identification of pancreatic cancer stem cells. Cancer research 2007, 67. 1030-7, DOI: 10.1158/0008-5472.CAN-06-2030; (d) C. A. O'Brien, A. Pollett, S. Gallinger, J. E. Dick, A human colon cancer cell capable of initiating tumour growth in immunodeficient mice. Nature 2007, 445. 106-10, DOI: 10.1038/nature05372.

5. (a) M. Locke, M. Heywood, S. Fawell, I. C. Mackenzie, Retention of intrinsic stem cell hierarchies in carcinoma-derived cell lines. Cancer research 2005, 65. 8944-50, DOI: 10.1158/0008-5472.CAN-05-0931; (b) M. E. Prince, R. Sivanandan, A. Kaczorowski, G. T. Wolf, M. J. Kaplan, P. Dalerba, I. L. Weissman, M. F. Clarke, L. E. Ailles, Identification of a subpopulation of cells with cancer stem cell properties in head and neck squamous cell carcinoma. Proceedings of the National Academy of Sciences of the United States of America 2007, 104. 973-8, DOI: 10.1073/pnas.0610117104; (c) L. J. Harper, K. Piper, J. Common, F. Fortune, I. C. Mackenzie, Stem cell patterns in cell lines derived from head and neck squamous cell carcinoma. Journal of oral pathology \& medicine : official publication of the International Association of Oral Pathologists and the American Academy of Oral Pathology 2007, 36. 594-603, DOI: 10.1111/j.1600-0714.2007.00617.x.

6. L. J. Harper, D. E. Costea, L. Gammon, B. Fazil, A. Biddle, I. C. Mackenzie, Normal and malignant epithelial cells with stem-like properties have an extended G2 cell cycle phase that is associated with apoptotic resistance. BMC cancer 2010, 10. 166, DOI: 10.1186/14712407-10-166.

7. (a) E. Quintana, M. Shackleton, M. S. Sabel, D. R. Fullen, T. M. Johnson, S. J. Morrison, Efficient tumour formation by single human melanoma cells. Nature 2008, 456. 593-8, DOI: 10.1038/nature07567; (b) M. R. Alison, S. Islam, N. A. Wright, Stem cells in cancer: instigators and propagators? Journal of cell science 2010, 123. 2357-68, DOI: 10.1242/jcs.054296.

8. M. R. Clay, M. Tabor, J. H. Owen, T. E. Carey, C. R. Bradford, G. T. Wolf, M. S. Wicha, M. E. Prince, Single-marker identification of head and neck squamous cell carcinoma cancer stem cells with aldehyde dehydrogenase. Head Neck 2010, 32. 1195-201, DOI: 10.1002/hed.21315.

9. M. H. Tabor, M. R. Clay, J. H. Owen, C. R. Bradford, T. E. Carey, G. T. Wolf, M. E. Prince, Head and neck cancer stem cells: the side population. Laryngoscope 2011, 121. 527-33, DOI: 10.1002/lary.21032.

10. M. Shackleton, E. Quintana, Progress in understanding melanoma propagation. Molecular oncology 2010, 4. 451-7, DOI: 10.1016/j.molonc.2010.06.006.

11. (a) L. R. Strachan, K. J. Scalapino, H. J. Lawrence, R. Ghadially, Rapid adhesion to collagen isolates murine keratinocytes with limited 
long-term repopulating ability in vivo despite high clonogenicity in vitro. Stem cells 2008, 26. 235-43, DOI: 10.1634/stemcells.2007-0534; (b) T. Igarashi, S. Shimmura, S. Yoshida, M. Tonogi, N. Shinozaki, G. Y. Yamane, Isolation of oral epithelial progenitors using collagen IV. Oral Dis 2008, 14. 413-8, DOI: 10.1111/j.1601-0825.2007.01390.x; (c) S. E. Chang, Y. Kim Pak, H. W. Lee, J. H. Choi, E. J. Jeong, S. H. Choi, H. W. Chang, Y. S. Chung, S. Y. Kim, Reduced mitochondrial properties in putative progenitor/stem cells of human keratinocytes. Ann Dermatol 2009, 21. 364-8, DOI: 10.5021/ad.2009.21.4.364.

12. Z. Wu, K. Shao, G. Song, [Adhesion of hepatocellular carcinoma cells to collagen IV coated surfaces]. Zhonghua Yi Xue Za Zhi 1999, 79. 369-72.

13. P. H. Jones, F. M. Watt, Separation of human epidermal stem cells from transit amplifying cells on the basis of differences in integrin function and expression. Cell 1993, 73. 713-24.

14. (a) P. HA, Dielectrophoresis. Cambridge: Cambridge University Press 1978; (b) H. MP, Nanoelectromechanics in Engineering and Biology. Boca Raton: CRC Press 2002; (c) J. TB, Electromechanics of Particles. Cambridge: Cambridge University Press 1995.

15. L. M. Broche, F. H. Labeed, M. P. Hughes, Extraction of dielectric properties of multiple populations from dielectrophoretic collection spectrum data. Phys Med Biol 2005, 50. 2267-74, DOI: 10.1088/00319155/50/10/006.

16. H. A. Pohl, I. Hawk, Separation of living and dead cells by dielectrophoresis. Science 1966, 152. 647-9, DOI: 10.1126/science.152.3722.647-a.

17. F. H. Labeed, H. M. Coley, H. Thomas, M. P. Hughes, Assessment of multidrug resistance reversal using dielectrophoresis and flow cytometry. Biophysical journal 2003, 85. 2028-34, DOI: 10.1016/S00063495(03)74630-X.

18. F. Yang, X. Yang, H. Jiang, P. Bulkhaults, P. Wood, W. Hrushesky, G. Wang, Dielectrophoretic separation of colorectal cancer cells. Biomicrofluidics 2010, 4. 13204, DOI: 10.1063/1.3279786.

19. P. R. Gascoyne, X. B. Wang, Y. Huang, F. F. Becker, Dielectrophoretic Separation of Cancer Cells from Blood. IEEE Trans Ind Appl 1997, 33. 670-678, DOI: 10.1109/28.585856.

20. L. A. Flanagan, J. Lu, L. Wang, S. A. Marchenko, N. L. Jeon, A. P. Lee, E. S. Monuki, Unique dielectric properties distinguish stem cells and their differentiated progeny. Stem cells 2008, 26. 656-65, DOI: 10.1634/stemcells.2007-0810.

21. A. Salmanzadeh, E. S. Elvington, P. C. Roberts, E. M. Schmelz, R. V. Davalos, Sphingolipid metabolites modulate dielectric characteristics of cells in a mouse ovarian cancer progression model. Integrative biology : quantitative biosciences from nano to macro 2013, 5. 843-52, DOI: $10.1039 / \mathrm{c} 3 \mathrm{ib00008g}$.

22. H. J. Mulhall, F. H. Labeed, B. Kazmi, D. E. Costea, M. P. Hughes, M. P. Lewis, Cancer, pre-cancer and normal oral cells distinguished by dielectrophoresis. Anal Bioanal Chem 2011, 401. 2455-63, DOI: 10.1007/s00216-011-5337-0.

23. S. E. Chang, S. Foster, D. Betts, W. E. Marnock, DOK, a cell line established from human dysplastic oral mucosa, shows a partially transformed non-malignant phenotype. International journal of cancer. Journal international du cancer 1992, 52. 896-902.

24. S. S. Prime, S. V. Nixon, I. J. Crane, A. Stone, J. B. Matthews, N. J. Maitland, L. Remnant, S. K. Powell, S. M. Game, C. Scully, The behaviour of human oral squamous cell carcinoma in cell culture. The Journal of pathology 1990, 160. 259-69, DOI: 10.1002/path.1711600313. 25. D. Sapkota, D. E. Costea, M. Blo, O. Bruland, J. B. Lorens, E. N. Vasstrand, S. O. Ibrahim, S100A14 inhibits proliferation of oral carcinoma derived cells through G1-arrest. Oral oncology 2012, 48. 21925, DOI: 10.1016/j.oraloncology.2011.10.001.

26. D. E. Costea, A. O. Dimba, L. L. Loro, O. K. Vintermyr, A. C. Johannessen, The phenotype of in vitro reconstituted normal human oral epithelium is essentially determined by culture medium. Journal of oral pathology \& medicine : official publication of the International Association of Oral Pathologists and the American Academy of Oral Pathology 2005, 34. 247-52, DOI: 10.1111/j.1600-0714.2005.00308.x.

27. D. E. Costea, L. L. Loro, E. A. Dimba, O. K. Vintermyr, A. C. Johannessen, Crucial effects of fibroblasts and keratinocyte growth factor on morphogenesis of reconstituted human oral epithelium. The Journal of investigative dermatology 2003, 121. 1479-86, DOI: 10.1111/j.15231747.2003.12616.x.

28. F. H. Labeed, H. M. Coley, M. P. Hughes, Differences in the biophysical properties of membrane and cytoplasm of apoptotic cells revealed using dielectrophoresis. Biochim Biophys Acta 2006, 1760. 9229, DOI: 10.1016/j.bbagen.2006.01.018.

29. K. F. Hoettges, Y. Hubner, L. M. Broche, S. L. Ogin, G. E. Kass, M. P. Hughes, Dielectrophoresis-activated multiwell plate for label-free high-throughput drug assessment. Anal Chem 2008, 80. 2063-8, DOI: 10.1021/ac702083g.

30. D. S. Kim, H. J. Cho, H. R. Choi, S. B. Kwon, K. C. Park, Isolation of human epidermal stem cells by adherence and the reconstruction of skin equivalents. Cell Mol Life Sci 2004, 61. 2774-81, DOI: 10.1007/s00018-004-4288-4.

31. D. K. Lieu, L. A. Degraffenried, R. R. Isseroff, E. A. Kurzrock, Beta1 integrin expression pattern in transitional urothelium does not allow for efficient stem cell enrichment as in other epithelia. Tissue engineering 2007, 13. 263-70, DOI: 10.1089/ten.2006.0132.

32. S. P. Desai, M. D. Vahey, J. Voldman, Electrically addressable vesicles: tools for dielectrophoresis metrology. Langmuir 2009, 25. 3867 75, DOI: 10.1021/la803330c.

33. G. Teti, C. Cavallo, B. Grigolo, S. Giannini, A. Facchini, A. Mazzotti, M. Falconi, Ultrastructural analysis of human bone marrow mesenchymal stem cells during in vitro osteogenesis and chondrogenesis. Microscopy research and technique 2012, 75. 596-604, DOI: 10.1002/jemt.21096.

34. A. M. Marzesco, P. Janich, M. Wilsch-Brauninger, V. Dubreuil, K. Langenfeld, D. Corbeil, W. B. Huttner, Release of extracellular membrane particles carrying the stem cell marker prominin-1 (CD133) from neural progenitors and other epithelial cells. Journal of cell science 2005, 118. 2849-58, DOI: 10.1242/jcs.02439.

35. A. Ruiz i Altaba, V. Palma, N. Dahmane, Hedgehog-Gli signalling and the growth of the brain. Nature reviews. Neuroscience 2002, 3. 2433, DOI: $10.1038 / \mathrm{nrn} 704$.

36. D. Corbeil, K. Roper, A. Hellwig, M. Tavian, S. Miraglia, S. M. Watt, P. J. Simmons, B. Peault, D. W. Buck, W. B. Huttner, The human AC133 hematopoietic stem cell antigen is also expressed in epithelial cells and targeted to plasma membrane protrusions. The Journal of biological chemistry 2000, 275. 5512-20.

37. E. J. Hagedorn, H. Yashiro, J. W. Ziel, S. Ihara, Z. Wang, D. R. Sherwood, Integrin acts upstream of netrin signaling to regulate 
formation of the anchor cell's invasive membrane in C. elegans. Developmental cell 2009, 17. 187-98, DOI: 10.1016/j.devcel.2009.06.006.

38. (a) S. A. Mani, W. Guo, M. J. Liao, E. N. Eaton, A. Ayyanan, A. Y. Zhou, M. Brooks, F. Reinhard, C. C. Zhang, M. Shipitsin, L. L. Campbell, K. Polyak, C. Brisken, J. Yang, R. A. Weinberg, The epithelial-mesenchymal transition generates cells with properties of stem cells. Cell 2008, 133. 704-15, DOI: 10.1016/j.cell.2008.03.027; (b) A. Biddle, I. C. Mackenzie, Cancer stem cells and EMT in carcinoma. Cancer metastasis reviews 2012. DOI: 10.1007/s10555-012-9345-0.

39. F. H. Labeed, J. Lu, H. J. Mulhall, S. A. Marchenko, K. F. Hoettges, L. C. Estrada, A. P. Lee, M. P. Hughes, L. A. Flanagan, Biophysical characteristics reveal neural stem cell differentiation potential. PloS one 2011, 6. e25458, DOI: 10.1371/journal.pone.0025458. 